\title{
AMORISMO: A Construção de um Índice Emocional por Meio do Mapeamento Socioemocional
}

\author{
Cecilia Decarli ${ }^{1}$ \\ Cristiano da Cruz Fraga ${ }^{2}$ \\ Juliano Santos do Carmo ${ }^{3}$
}

\begin{abstract}
RESUMO
Este artigo tem por objetivo analisar a importância do diagnóstico socioemocional para compreensão de comportamentos e processos de desenvolvimento e aprendizagem de alunos do Ensino Fundamental. A construção do índice emocional ocorreu mediante o mapeamento socioemocional obtido por meio de oficinas de afetividade ministradas para 63 alunos de $7^{\circ \mathrm{s}}$ anos do Ensino Fundamental de uma escola pública do município de Campo Bom-RS. O índice foi elaborado a partir de uma abordagem quali-quantitativa (mista) de pesquisa, mediante os resultados obtidos nas oficinas aplicadas, considerando a importância da concepção do amorismo para o ensino, por meio da educação socioemocional no ensino básico. Foram obtidos como resultados do índice emocional: 5 alunos com conceito muito bom, 50 com conceito bom e 8 com conceito ruim. Os dados advindos da aplicação do índice emocional aqui proposto poderão ser úteis para estabelecer um novo olhar aos alunos envolvidos que, porventura, apresentarem lacunas de cunho social e emocional. Dessa forma, os professores terão acesso aos perfis individuais e poderão potencializar o processo de ensino-aprendizagem mediante práticas pedagógicas que abordem as competências afetivas e socioemocionais. $O$ índice emocional apresentado neste estudo pode ser replicado a outros contextos e realidades educacionais, tornando-se um método de aplicação no ensino.
\end{abstract}

Palavras-chave: Amorismo. Oficinas de afetividade. Ensino Fundamental. Índice emocional.

\section{LOVENESS: THE CONSTRUCTION OF AN EMOTIONAL INDEX THROUGH A SOCIOEMOTIONAL MAPPING}

\section{ABSTRACT}

This paper aims at analysing the importance of the socioemotional diagnostic to understand behaviours and development and learning processes of elementary school students. The construction of an emotional index occurred through a socioemotional mapping obtained by affection workshops presented to 63 7th grade students of a public school in Campo Bom - RS. The index was developed based on a quali-quantitative (blended) approach, according to the results obtained in the applied workshops, taking into consideration the importance of the concept of Loveness in teaching, through socio-emotional education in elementary school. The results of the emotional index were: 5 students with a very good concept, 50 with a good concept and 8 with a bad concept. The data from the emotional index proposed here may be useful to establish a new view to the involved students who, by any chance, may present social and emotion deficiencies. In this way, the teachers will have access to individual profiles and may be able to maximize the teaching-learning through pedagogical practices that approach affective and socioemotional competencies. The emotional index presented in this study can be replicated to other educational contexts and realities, turning, this way, into an application method in teaching.

Keywords: Loveness. Affectivity Workshops. Elementary School. Emotional Index.

Recebido em: 29/3/2020

Aceito em: $1 \% / 6 / 2020$

\footnotetext{
1 Autora correspondente. Universidade Federal do Rio Grande do Sul - UFRGS (PPGEC). Rua Ramiro Barcelos, 2600 - Prédio Anexo - Santa Cecília. Porto Alegre/RS, Brasil. CEP 90035-003. http://lattes.cnpq.br/2758211982533095. https://orcid.org/0000-0003-4941-8419. cecilia_decarli@hotmail.com

2 Universidade Federal do Rio Grande do Sul - UFRGS (PPGEC). Porto Alegre/RS, Brasil. http://lattes.cnpq.br/8393374920440134. https:// orcid.org/0000-0001-8657-9831.

3 Universidade Federal de Pelotas - UFPel. Pelotas/RS, Brasil. http://lattes.cnpq.br/7477981517627461. http://orcid.org/0000-0001-6926-0298.
} 
O presente estudo trata da importância das relações afetivas, por meio da compreensão do conceito de amor no ambiente escolar mediante um diálogo entre autores dos campos de Educação e Filosofia Educacional. Para tanto, inicialmente, apresentaremos algumas ideias e conceitos importantes que são fulcrais para a compreensão de nossa perspectiva. Em seguida, passaremos a descrever a importância das relações afetivas no ambiente escolar à luz de achados recentes na neurociência e na Psicologia Cognitiva, os quais nos estimularam a construir uma ferramenta de expressão e diagnóstico socioemocional para alunos do Ensino Fundamental.

Entendemos por amorismo a transposição da afetividade nos processos de ensino-aprendizagem, mediante o estabelecimento de vínculos reais de amor e objetivando o desejo pelo aprender. A geração de vínculos afetivos com os alunos é requisito primordial para o bom andamento das aulas e é garantia de um ensino mais prazeroso e efetivo para os alunos, uma vez que aprender com amor potencialmente gera confiança e respeito na relação aluno/educador (FRAGA; DECARLI, 2018).

$\mathrm{O}$ amor é um conceito que possui diversos escopos na literatura em geral. Alguns autores, especialmente filósofos, psicólogos e psicanalistas, apresentam conceitos interessantes que podem ser aplicados no campo educacional, uma vez que parece indiscutível que o processo de ensino-aprendizagem se constrói por intermédio de relações humanísticas.

Segundo Lacan, citado por Safatle (2016):

O amor é, segundo Lacan, uma relação que nos desampara, mas que nos recria. A reflexão sobre o amor demonstra seu interesse político na medida em que abre a compreensão para formas de reconhecimento entre sujeitos que, ao menos por um momento, deixam de querer ser determinados como pessoas individualizadas (p. 26).

Essa definição, no âmbito do processo de ensino, mostra que as relações de afetos e desafetos nos grupos sociais são norteadoras para o convívio em sociedade, especialmente quando o indivíduo ama, por conseguinte, sente prazer pelas relações estabelecidas na escola e reconhece maior significado na busca do conhecimento.

Segundo Immanuel Kant - um dos principais filósofos da era moderna - existem diversas figuras do amor. Uma de suas principais ideias era a de que não é necessário amar sensivelmente para fazer o bem, no entanto, por meio do ato de fazer o bem, é possível despertar sentimentos de simpatia pelo ser humano, os quais podem ser utilizados pelo agente para impulsionar ações morais que potencialmente levam a uma relação de respeito, sendo os sentimentos de prazer e desprazer aqueles que podem fomentar boas ações (BORGES, 2000). A perspectiva kantiana assim concebida leva-nos a crer que aulas prazerosas, com estabelecimento de vínculos harmoniosos e de amor por parte daquele que faz o bem entre os sujeitos envolvidos, podem levar a um processo de ensino-aprendizagem de qualidade.

Lembranças marcantes e significativas da trajetória escolar estão intimamente ligadas a vínculos afetivos. Relatos de alunos do Ensino Fundamental demonstram a influência e positividade que professores exerceram na sua vida ao usarem práticas pedagógicas envolvendo afetividade no ensino. Essa é uma evidência importante de que 
atos carinhosos dentro e fora da escola (dentro do escopo do que denominamos "amorismo") sejam um meio eficaz para atingir uma aprendizagem significativa no ensino básico (FRAGA; DECARLI, 2018).

A vida emocional está conectada a processos psicológicos e ao desenvolvimento da consciência. Não é possível separar o pensamento do afeto, dado que isso parece negar a possibilidade de estudar a influência inversa do pensamento no plano afetivo, mostrando assim que o indivíduo é resultado do processo afetivo, mental, cognitivo e físico, interno e externo (VYGOTSKY, 2003).

Segundo Pantano e Assencio-Ferreira (2009), é necessário oferecer estímulos coerentes para cada faixa etária, pois as crianças que "pulam" estágios do desenvolvimento apresentam dificuldades de recuperação, o que potencialmente gera uma aprendizagem incompleta e imatura, com a sua ressignificação sendo difícil de ser realizada.

Para estabelecer quali-quantitativamente o perfil emocional do aluno, o professor/educador precisa considerá-lo como protagonista de seu conhecimento/aprendizado e, por sua vez, isso é importante para estabelecer metas e planejamento de atividades para o trabalho pedagógico.

Cosenza e Guerra (2011) constataram que o cérebro aprende em consonância com as emoções:

Sabemos que no momento em que recebemos uma carga emocional ficamos mais
vigilantes e que nossa atenção está voltada para os detalhes considerados impor-
tantes, pois as emoções controlam os processos motivacionais. Além disso, sabe-se
que a amígdala interage com o hipocampo e pode mesmo influenciar o processo
de consolidação da memória. Portanto uma pequena excitação pode ajudar no es-
tabelecimento e conservação de uma lembrança (COSENZA; GUERRA, 2011, p. 83).

A emoção afeta a cognição. Quando um aluno experiencia uma situação de aprendizagem que envolve uma emoção, positiva ou negativa, a amígdala controla essa memória de alguma forma e, consequentemente, a memória afetada pela amígdala é permanentemente incorporada ao conhecimento esquemático da aprendizagem de uma área temática. Isso, por sua vez, afetará todos os outros processos de aprendizagem relacionados a esse assunto. Um aumento na atenção do aluno a um episódio de aprendizagem (ensino) é impulsionado pela emoção, porque quando um aluno é despertado por um tópico, o sistema endócrino libera níveis moderados de adrenalina. Isso resulta em um aumento na atenção, o que, por sua vez, ajudará os alunos a aprenderem conceitos mais plenamente (SASIKUMAR; FATHIMA; MOHAN, 2013).

As consequências de não trabalhar a questão socioemocional com os alunos acarretam em dificuldades de concentração e desmotivação com o que é proposto na escola, pois um aluno que enfrenta muitos problemas de origem afetiva no seu vínculo social terá dificuldades cognitivas em relação aos estudos. Daí a importância de se estabelecer, como educador, um mapeamento socioemocional adequado dos alunos.

A literatura traz muitas teorias sobre educação afetiva e muitos estudos qualitativos. Ribeiro (2010), por exemplo, analisa documentos científicos e governamentais sobre a afetividade na aprendizagem escolar. Amorim e Navarro (2012) realizam uma revisão bibliográfica da afetividade na educação infantil. Sarnosky (2014) faz uma abor- 
dagem da afetividade nos espaços de ensino-aprendizagem. Fraga e Decarli (2018) fazem uma análise de como o aluno se sente em relação às relações afetivas abordadas no espaço escolar.

O estudo de Silva, Cruz e Silva (2014) também utiliza uma abordagem qualitativa. O texto estabelece uma abordagem sociocognitiva dentro da dimensão afetiva utilizando o Diagrama Afeto-Performance (DAP) com alunos de Ensino Médio. Ao descrever quali-quantitativamente o perfil emocional do aluno, procuramos lançar subsídios para que o professor possa atender às necessidades socioemocionais dos aprendizes de acordo com os valores expostos no índice emocional.

Diante do exposto, este estudo tem por objetivo analisar a importância do diagnóstico socioemocional para compreensão de comportamentos e processos de desenvolvimento e aprendizagem de alunos do Ensino Fundamental. A análise ocorreu por meio de um mapeamento socioemocional, mediante a aplicação de oficinas de afetividade e desenvolvimento de um índice emocional individual dos alunos.

Nosso estudo gerou um instrumento importante de expressão para o uso em sala de aula. Por ocasião das oficinas de afetividade, os alunos relataram questões socioemocionais que vivenciam no dia a dia. O uso de um método de diagnóstico emocional, por meio do índice, traçou o perfil emocional de cada aluno, o que viabilizou um conhecimento mais profundo da realidade pessoal de cada um e nos permitiu pensar em intervenções importantes que pudessem auxiliar no processo de motivação pelo ensino-aprendizagem. Esta ferramenta pode ser utilizada por docentes e gestores escolares de diversas áreas e níveis de ensino, fornecendo subsídios para criar novas intervenções afetivas e efetivas ao processo de ensino e aprendizagem.

\section{AFETIVIDADE E NEUROCIÊNCIA}

As emoções originam-se no cérebro, especificamente no sistema límbico, localizado próximo ao tronco cerebral. É ele que controla o estado de alerta e a excitação e que envia mensagens sensoriais ao córtex. Muito de nosso pensamento e aprendizagem ocorre no córtex. A memória, um componente importante da aprendizagem, também está relacionada ao sistema límbico, o responsável por regular as emoções (SASIKUMAR; FATHIMA; MOHAN, 2013).

O sistema límbico contém o complexo da amígdala, o hipocampo, o tálamo e o hipotálamo. O complexo da amígdala é uma das principais áreas de processamento de conteúdo emocional do comportamento e da memória. O hipocampo e a amígdala podem moldar memórias, combinando a versão emocional da amígdala com a versão mais objetiva do hipocampo. Devido ao efeito da amígdala na memória, o estado emocional do aprendiz irá alterar a percepção da memória pelos sujeitos. O tálamo observa estímulos externos, diz ao cérebro o que está acontecendo fora do corpo e transmite, de forma imediata, informações limitadas à amígdala, o que pode desencadear uma explosão emocional rápida. O hipotálamo informa ao cérebro o que está acontecendo dentro do corpo e, quando registra um estímulo, o cérebro tenta produzir uma reação. Quando nenhuma reação pode ser produzida, o hipotálamo acionará o sistema endócrino para liberar hormônios. Cortisol, endorfinas e adrenalina são hormônios que afetam o comportamento humano e a aprendizagem (especialmente na inibição da produção 
do neurotransmissor serotonina, o qual é fundamental para a produção de novas sinapses). O cortisol é um hormônio que é liberado quando um indivíduo experimenta o estresse (SASIKUMAR; FATHIMA; MOHAN, 2013). Os níveis crônicos de cortisona podem destruir os neurônios do hipocampo que estão associados à memória e à aprendizagem (VINCENT, 1990).

António Damásio (2004, p. 91) dedica-se a estudar o papel das emoções e dos sentimentos no funcionamento cognitivo. O neurocientista português estudou uma série de pacientes com lesões cerebrais localizadas na área pré-frontal, considerada fundamental para o raciocínio. Em todos os casos ele encontrou uma importante redução da atividade emocional, o que o levou à conclusão de que existe uma profunda interação entre ambos os sistemas cognitivos: racional e emocional. Para ele:

Os sentimentos, no sentido em que a palavra é usada aqui, emergem das mais variadas reações homeostáticas, não somente das reações que chamamos emoções no sentido restrito do termo. De um modo geral os sentimentos traduzem o estado da vida na linguagem do espírito (DAMÁSIO, 2004, p. 91).

As emoções humanas compreendem complexas interações de sentimentos subjetivos, bem como respostas fisiológicas e comportamentais que são especialmente desencadeadas por estímulos externos, os quais são subjetivamente percebidos como "pessoalmente significativos" (TYNG et al., 2017).

As emoções têm uma influência substancial sobre os processos cognitivos nos seres humanos. Incluem percepção, atenção, aprendizagem, memória, raciocínio e resolução de problemas, tendo influência forte na atenção, especialmente na seletividade da atenção, além de motivar a ação e o comportamento. Esse controle atencional e executivo está intimamente ligado aos processos de aprendizagem, pois a capacidade de atenção é ligada às informações relevantes. A emoção também facilita a codificação e ajuda a recuperar informações de forma eficiente (TYNG et al., 2017).

A linha da Psicologia positiva ressalta que, no passado, os psicólogos se interessavam bem mais pelo funcionamento negativo da personalidade ou pelas emoções negativas (depressão, desânimo, ansiedade, solidão, agressividade, ira, culpa e timidez) do que pelas emoções positivas (bem-estar, satisfação com a vida, felicidade, alegria, otimismo, esperança, sabedoria, amor e perdão), nos tempos atuais a abordagem positiva permite melhores resultados sobre o comportamento humano (OLIVEIRA, 2004).

Acredita-se que a emoção não regulamentada nos alunos seja a causa de muitas formas de mau comportamento. As emoções podem afetar o aprendizado, de maneira positiva ou negativa. Quando um aluno experimenta emoções positivas, o processo de aprendizagem pode ser aprimorado, mas quando experimenta emoções negativas, o processo de aprendizagem pode ser desativado (SASIKUMAR; FATHIMA; MOHAN, 2013).

O sujeito constitui-se como um ser intelectual e afetivo, que pensa e sente simultaneamente. Reconhecer a afetividade como parte integrante do processo de construção do conhecimento implica um outro olhar sobre a prática pedagógica que não se restringe apenas ao processo de ensino-aprendizagem na dimensão cognitiva. Dentro da abordagem construtivista, a preocupação com a forma de ensinar é tão importante quanto o conteúdo a ser ensinado, levando em consideração a intensidade das rela- 
ções, os aspectos emocionais, a dinâmica das manifestações e as formas de comunicação, que passam a ser pressupostos para o processo de construção do conhecimento (SARNOSKI, 2014).

Santos e Primi (2014) evidenciam algumas habilidades socioemocionais, resultantes de uma ampla análise fatorial originando uma hipótese de que os principais traços de personalidade de seres humanos estão relacionados com essas cinco grandes habilidades: Abertura a experiências: estar disposto e interessado pelas experiências - curiosidade, imaginação, criatividade e prazer pelo aprender; Conscienciosidade: ser organizado, esforçado e responsável pela própria aprendizagem - perseverança, autonomia, autorregulação e controle da impulsividade; Extroversão: orientar os interesses e energia para o mundo exterior - autoconfiança, sociabilidade, entusiasmo; Amabilidade - Cooperatividade: atuar em grupo de forma cooperativa e colaborativa - tolerância, simpatia, altruísmo e Estabilidade emocional: demonstrar previsibilidade e consistência nas reações emocionais - autocontrole, calma e serenidade.

Abed (2016) enfatiza que a preocupação de considerar as habilidades socioemocionais no processo de aprendizagem não deve ser percebida como mais um item a ser trabalhado na rotina pesada do professor, mas sim como uma contribuição na busca de um ambiente mais saudável e tranquilo, o qual possa favorecer uma aprendizagem mais significativa.

\section{METODOLOGIA}

O presente estudo foi realizado na Escola Municipal de Ensino Fundamental Presidente Vargas, em Campo Bom/RS, e contou com a participação de 63 alunos de $7^{\circ} \mathrm{s}$ anos do Ensino Fundamental, com faixa etária entre 12-15 anos. Foram aplicadas 5 oficinas de afetividade em semanas consecutivas, com duração de 50 minutos cada uma. As oficinas ocorreram nos dois primeiros períodos de aula do turno letivo, uma vez que nesse horário o cérebro humano está mais estimulado e os alunos ainda não estão agitados.

De acordo com Freitas e Dias (2010), a prática pedagógica de oficinas propicia a exposição de ideias, conceitos e experiências sem julgamentos, facilitando a transformação de preconceitos pela via reflexiva e de socialização de saberes e de experiências. Sendo assim, podemos fazer sondagens de cunho socioemocional da vida pessoal dos alunos sem sermos invasivos, posto que o aluno vai relatando o que deseja ao longo da aplicação, em interação com o docente aplicador.

As oficinas aplicadas foram adaptadas do projeto Oficinas de Afetividade, do professor Nourival Cardozo Junior, que foram criadas com o intuito de viajar pelo território das emoções com os alunos que ele atende nas suas aulas, tendo como objetivo resgatar a autoestima e liberar o desejo de aprender, sendo usadas para compreender os alunos e registrar os sentimentos trazidos pelos docentes pós-aplicação (JUNIOR, 2006). Após a aplicação analisamos os dados individuais de cada aluno e elencamos pesos numéricos para as respostas das oficinas, que por fim geraram um conceito emocional final para cada aluno, utilizando uma abordagem quali-quantitativa (mista) de pesquisa. 
Fonseca (2002) difere a pesquisa qualitativa da quantitativa, explicando que na quantitativa os dados são quantificados, e como as amostras geralmente são grandes e representativas, os resultados tornam-se um retrato real do todo. Além de centrada na objetividade, considera como base os dados brutos e recorre à Matemática para descrever um fenômeno e suas variáveis. Recorrer à pesquisa qualitativa e quantitativa juntas é interessante, uma vez que fornecem mais informações do que quando utilizadas isoladamente.

As oficinas buscaram trazer emoções vividas pelos alunos na atualidade, elencando emoções diárias, analisando tristezas e problemas anteriores, obstáculos atuais e como eles se viam diante do olhar da sociedade, abordando assim diversas emoções e vínculos sociais presentes no período em que se encontravam no momento da aplicação.

1 - Disco da Afetividade: Foi entregue aos alunos um disco contendo 8 frases de cunho socioemocional. $O$ aplicador leu e explicou o significado de cada uma. As frases do disco foram: Participa de atividades em grupos; verbaliza seus sentimentos; sorri com espontaneidade; é tolerante no trato com as pessoas; cumprimenta espontaneamente as pessoas; emociona-se com histórias; abraça ou toca as pessoas; esforça-se para ajudar as pessoas. Foi solicitado que colorissem de vermelho, amarelo e verde de acordo com a frequência que praticam as ações descritas.

2 - Minha Nada Mole Vida: Foi feita uma conversa inicial sobre os problemas emocionais que cada um traz consigo e após os alunos foram convidados a fazer uma pequena produção escrita sobre os problemas afetivos que vinham passando, tais como: perdas, medos, doenças, abandono e outros itens relevantes a sua história de vida.

3 - Escalando Montanhas: Os alunos foram convidados a desenhar três montanhas de tamanhos diferentes e foram elencando suas maiores dificuldades e obstáculos de acordo com a intensidade, referente ao tamanho da montanha. Após escreveram o que poderiam fazer para vencer estes obstáculos.

4 - Diário das Emoções: Os alunos receberam um diário de emoções, contendo um calendário de 7 dias (uma semana), no qual deveriam descrever diariamente as emoções vivenciadas, por meio de anotações e 4 "emojis", que significavam: dia muito feliz-alegre; dia normal-tranquilo; dia triste-melancólico/deprimido; dia chateado-raiva/revolta. Nessa oficina os alunos receberam as orientações e coloriram os emojis. O preenchimento foi feito em casa e entregue na semana seguinte.

5 - Eu sou um Iceberg: O aplicador mostrou uma imagem de iceberg e explicou seu significado, fazendo relação aos obstáculos enfrentados na vida. Os alunos desenharam um iceberg e escreveram como as pessoas os veem, na sua opinião, foram livres para expor tais sentimentos, sem ser enfatizada a quantidade de palavras.

Ao final das oficinas, o material produzido foi analisado quali-quantitativamente, gerando um método de diagnóstico emocional, denominado de índice de perfis socioemocionais dos alunos (metodologia criada pelos autores).

Na sequência apresenta-se a descrição da análise de cada oficina: 
O Disco da Afetividade possui oito partes, então atribuímos pontuação diferente por cor: verde - equivalente a 1,25 ponto, amarelo - equivalente a 0,625 ponto e vermelho - equivalente a 0 ponto, referente ao mapeamento do grau socioemocional de cada aluno, a fim de compor o índice final numericamente. A fórmula utilizada para ponderar a média final no disco da afetividade no Excel foi:

$$
=(((\mathrm{B} 2 * 1,25)+(\mathrm{C} 2 * 0,625)+(\mathrm{D} 2 * 0)))
$$

Para as oficinas Minha Nada Mole Vida e Escalando Montanhas criamos quatro perfis gerais referentes às emoções apresentadas:

Situações gravíssimas (0 ponto): Equivalente a relatos de pensamentos e atos suicidas, abuso sexual, atos criminais, depressão e abandono.

Situações graves (3 pontos): Equivalente a relatos de automutilação, perda de ente próximo, doenças graves no próprio indivíduo ou na família, situações de miséria, fome.

Situações médias (7 pontos): Equivalente a relatos de separação dos pais, exposição de sentimentos de raiva, poucos amigos, brigas com pais, irmãos e outras pessoas.

Situações leves (10 pontos): Equivalente a relatos de problemas cognitivos e escolares, morte de animais de estimação, dificuldades com esportes, doenças simples, preguiça, dificuldades com acompanhamento da rotina.

Para a oficina do Diário das Emoções consideramos a marcação dos emojis, que foram sete no total. Então, cada emoji teve um peso diferente também: Dia muito feliz (1,43 ponto), dia normal (0,95 ponto), dia triste $(0,47$ ponto) e dia chateado (0 ponto), valores referentes à soma de 10 pontos como na oficina do Disco da Afetividade. A fórmula utilizada no Excel para compor a média por aluno foi:

$=(((\mathrm{B} 2 * 1,43)+(\mathrm{C} 2 * 0,95)+(\mathrm{D} 2 * 0,47)+(\mathrm{E} 2 * 0)))$

Para a oficina Eu sou um Iceberg foram criados parâmetros de acordo com os sentimentos, qualidades e defeitos elencados pelos alunos, independentemente da quantidade exposta, onde:

$1=10$ pontos, aluno citou somente sentimentos bons e qualidades;

$2=7,5$ pontos, aluno citou na maioria sentimentos bons e qualidades;

$3=5$ pontos, aluno citou metade de sentimentos bons e qualidades e metade de sentimentos ruins e defeitos;

$4=2,5$ pontos, alunos citou na maioria sentimentos ruins e defeitos;

$5=0$ ponto, aluno citou somente sentimentos ruins e defeitos.

Para sentimentos como quieto, falante e tímido foram analisados os demais itens apresentados e levado em consideração que a falta de expressão oral pode acarretar em alguns problemas de relacionamento em grupos.

Os dados foram descritos em planilhas do Microsoft Excel (versão Excel 2010), nas quais os alunos foram identificados por números e turma; foram criadas fórmulas simples que permitiram a soma da pontuação para análise de cada oficina; ao final somamos a pontuação e dividimos pelo número de oficinas ministradas, que compõem o índice emocional final e individual de cada aluno, em que cada um obteve uma pontuação final de acordo com o perfil emocional gerado, sendo: 
0-2,5- muito ruim

2,6-5,0- ruim

5,1-7,5- bom

7,6-10- muito bom

\section{RESULTADOS E DISCUSSÕES}

A primeira oficina, intitulada Disco da Afetividade, teve por objetivo verificar como os alunos viam-se diante de ações e atitudes que deveriam tomar no dia a dia - que se remetem a emoções e sentimentos na convivência com a coletividade. Observamos uma grande quantidade de partes dos discos pintadas com a cor amarela, que representa que o aluno só expressa emoção às vezes referentes às ações que lhe geram sentimentos, seguida pela cor verde. Ainda nos impressiona, contudo, a quantidade de partes vermelhas no disco, que ficaram ausentes em apenas 4 deles. De um total de 503 partes, tivemos 325 delas como sentimentos que são realizados somente às vezes ou nunca pelos adolescentes que participaram do estudo (Figura 1), mostrando a falta de socialização e expressão de emoções importantes para convívio em sociedade.

Figura 1 - Gráfico representando o resultado geral das turmas referente à escolha das cores (considerando o total de 503 partes pintadas no total pelos 63 alunos envolvidos) na oficina 1- Disco da Afetividade

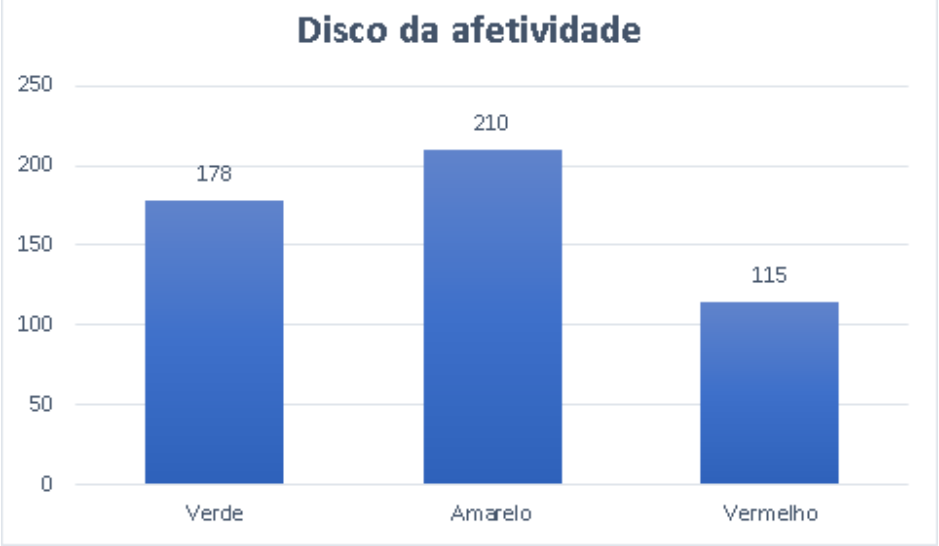

Fonte: Elaborada pelos autores (2020).

A oficina 2, intitulada Minha Nada Mole Vida, visou a verificar um problema atual que influencia na vida do aluno. A maioria apresentou problemas denominados como médios, seguidos pelos problemas graves. Já na oficina 3: Escalando Montanhas, visamos a trazer os três principais obstáculos de vida visualizados pelos alunos, em reflexão ao que vivenciam em seu meio social, que afetam seu emocional de alguma maneira. A maioria expôs problemas denominados como médios, seguidos de leves, em ambas as oficinas problemas gravíssimos aparecem em menos de 5 alunos, mas esse número aumenta nos problemas graves (Figura 2). Estes dados nos mostram que existem problemas de cunho socioemocional sendo enfrentados por pelo menos $1 / 4$ da turma, que podem influenciar na convivência em grupo no espaço escolar e também no processo de ensino-aprendizagem individual e em grupo. 
Figura 2 - Gráfico de resultados da turma referente às oficinas

2- Minha Nada Mole Vida e 3- Escalando Montanhas

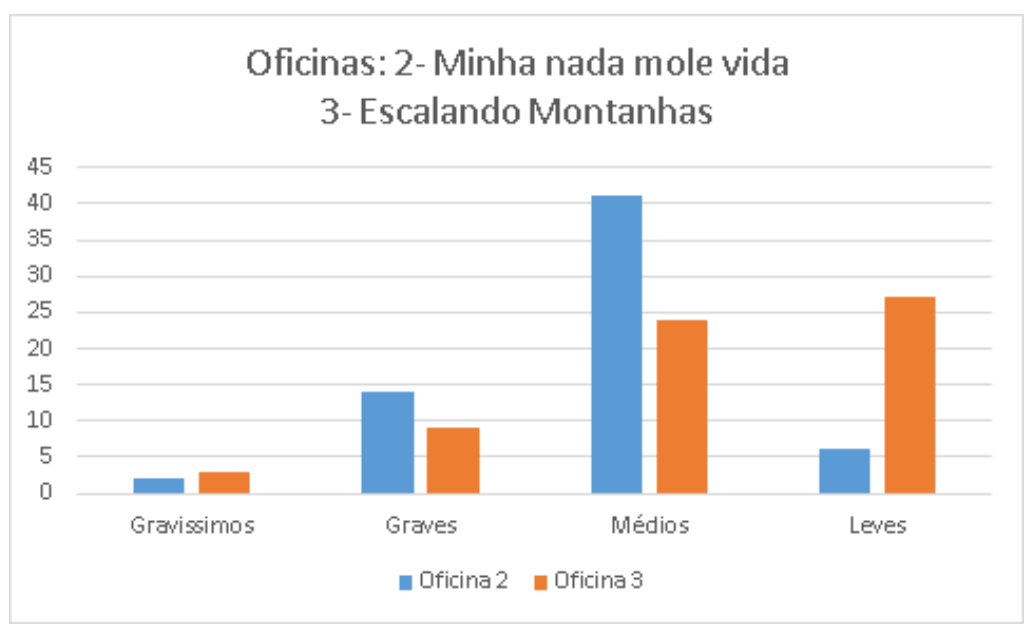

Fonte: Elaborada pelos autores (2020)

A oficina 4, intitulada de Diário das Emoções, teve por objetivo analisar o dia a dia do aluno, posto que nos trouxe uma reflexão de sete dias do aluno em relação ao sentimento elencado como o principal para cada dia. Os emojis que mais apareceram nas turmas estudadas foi o de dia normal (263), seguido pelo feliz (102), e em menor quantidade os emojis de dias tristes e chateados (74) (Figura 3). Analisando individualmente os diários, podemos verificar quais alunos tinham problemas frequentes na família, uma vez que estes não apareceram em relação ao espaço escolar. Os dados de observação individual de cada dia do aluno são bem interessantes para os docentes compreenderem como está acontecendo a convivência familiar do seu aluno.

Figura 3 - Gráfico representando o resultado geral da turma referente a escolha dos emojis (considerando o total de 439 emojis colocados nos diários, sendo que cada aluno colocou

7 por diário, no total pelos 63 alunos envolvidos), na oficina 4- Diário das Emoções

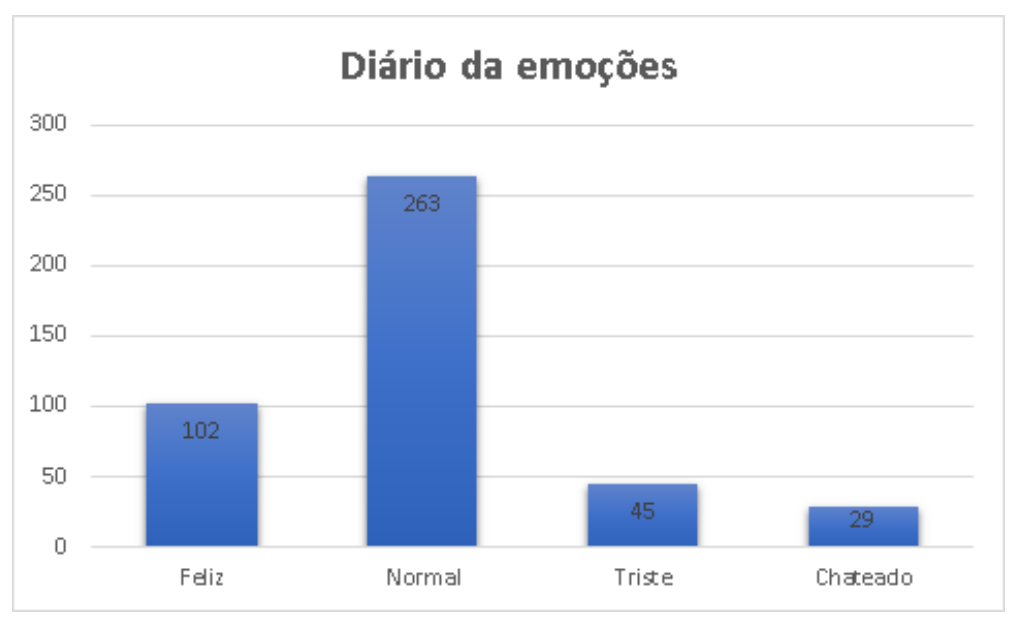

Fonte: Elaborada pelos autores (2020).

A oficina 5, intitulada Eu sou um Iceberg, teve por objetivo verificar como o aluno sentia-se visto em relação às demais pessoas com quem convive em sociedade. A maioria encontra-se no conceito 2 , trazendo sentimentos bons e qualidades, seguido pelos 
conceitos 3, 4 e 5, que revelam sentimentos ruins e defeitos, observando-se que somente seis alunos elencam apenas itens bons (Figura 4). Esses dados mostram a preocupação do adolescente em relação ao que a sociedade pensa a seu respeito. Apareceram alguns termos: "puta", "burro(a)", "chato(a)", "irritante", que revelam traços de uma sociedade preconceituosa, excludente e que apresenta dificuldades de convivência entre adultos e adolescentes.

Sabino (2012), em sua experiência com Psicologia Clínica em instituições públicas e privadas, relata que ouve muito que adultos não sabem interpretar crianças e o oposto também, que é o principal motivo de diálogos truncados, afetos congelados e relações humanas marcadas por impedimentos. Compreender o que os alunos pensam e o que gera condutas inadequadas no espaço escolar é um meio de aproximação entre professor/aluno que qualifica o processo de ensino-aprendizagem.

Figura 4 - Gráfico de resultados da turma referente à oficina 5- Eu sou um Iceberg, considerando: $1=$ aluno citou somente sentimentos bons e qualidades, $2=$ aluno citou na maioria sentimentos bons e qualidades, $3=$ aluno citou metade de sentimentos bons e qualidades e metade de sentimentos ruins e defeitos, $4=$ aluno citou na maioria sentimentos ruins e defeitos, $5=$ aluno citou somente sentimentos ruins e defeitos

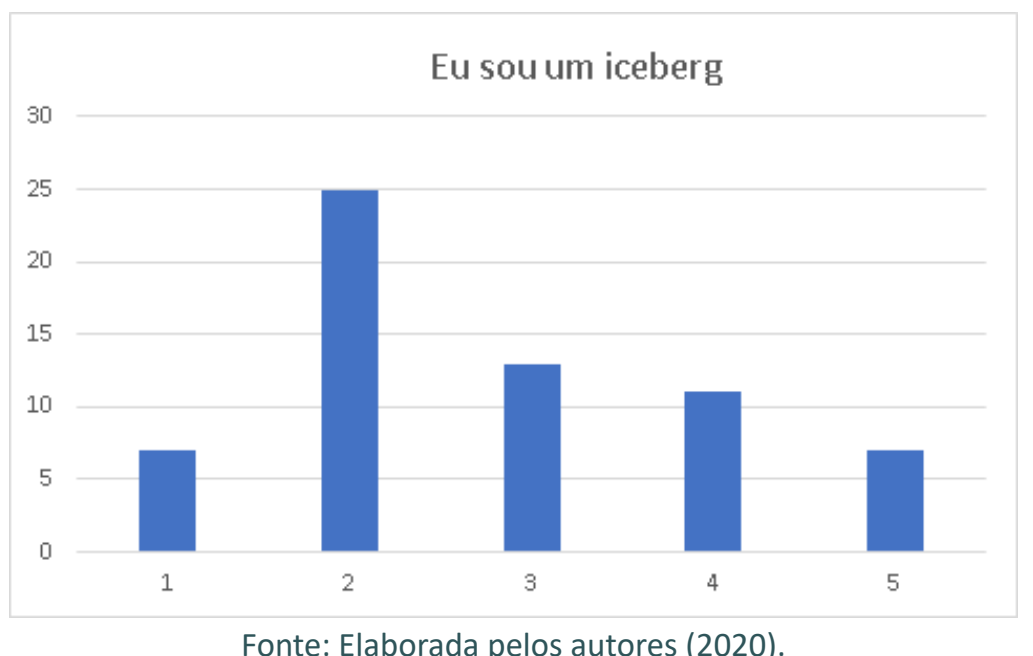

O resultado final do índice emocional mostra-nos que a grande maioria dos alunos tem um perfil emocional bom, uma vez que 50 alunos ficaram dentro do conceito bom, 8 no conceito ruim e 5 no conceito muito bom, destacando-se que nenhum ficou com o conceito muito ruim (Figura 5). Em relação ao grupo, podemos afirmar que são turmas que apresentam alunos com um conceito emocional a ser refletido pelos docentes e que o seu planejamento deve prever atividades que desenvolvam tais habilidades, que podem ser abordadas no coletivo.

Segundo Abed (2016), promover situações de debates e trocas de ideias em sala de aula gera o desenvolvimento de muitas habilidades de convívio social, e ainda permite ao professor ter acesso à forma de ser dos seus alunos, à maneira como eles se expressam perante o grupo, seus conhecimentos, ideias, valores, opiniões, impressões, sentimentos, posicionamentos, dúvidas, inquietações e tantos outros componentes do seu mundo interno. 
Figura 5 - Gráfico mostrando o índice emocional final dos alunos no contexto geral das duas turmas

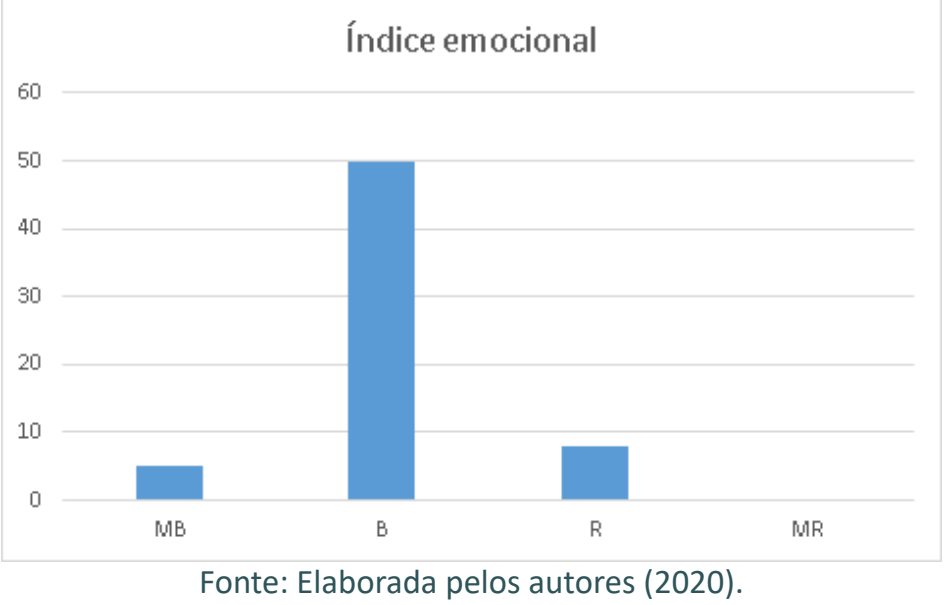

O índice individual final de cada aluno nos mostra alguns dados relevantes. Notamos que nenhum aluno atinge a pontuação máxima no índice, o que revela a necessidade de trabalhar as habilidades socioemocionais com todos os alunos das turmas. Também mostra que alguns alunos que atingiram o conceito bom estão no limite, chegando próximos do conceito ruim, e que apesar de não ter nenhum aluno no conceito muito ruim, temos pouquíssimos no conceito muito bom, evidenciando novamente que deve ser abordado o emocional no currículo (Tabela 1).

Tabela 1 - Resultado individual dos 63 alunos, mostrando o valor aos quais foram atribuídos os conceitos

\begin{tabular}{|c|c|c|c|c|c|c|c|}
\hline Aluno(a) & Oficina1 & Oficina2 & Oficina3 & Oficina4 & Oficina5 & Média & Conceito \\
\hline 1.1 & 7,5 & 7 & 10 & 6,17 & 5 & 7,134 & B \\
\hline 2.1 & 5,625 & 10 & 10 & 7,13 & 7,5 & 8,051 & MB \\
\hline 3.1 & 6,875 & 3 & 10 & 8,09 & 7,5 & 7,093 & B \\
\hline 4.1 & 8,125 & 7 & 7 & 7,61 & 7,5 & 7,447 & B \\
\hline 5.1 & 4,375 & 0 & 3 & 6,18 & 5 & 3,711 & R \\
\hline 6.1 & 4,375 & 3 & 3 & 7,13 & 2,5 & 4,001 & R \\
\hline 7.1 & 6,875 & 7 & 7 & 7,14 & 0 & 5,603 & B \\
\hline 8.1 & 6,875 & 3 & 7 & 8,09 & 7,5 & 6,493 & B \\
\hline 9.1 & 3,125 & 3 & 7 & 5,69 & 7,5 & 5,263 & B \\
\hline 10.1 & 7,5 & 7 & 7 & 6,65 & 2,5 & 6,13 & B \\
\hline 11.1 & 7,5 & 3 & 10 & 3,3 & 7,5 & 6,26 & B \\
\hline 12.1 & 5,625 & 7 & 10 & 6,65 & 5 & 6,855 & B \\
\hline 13.1 & 5,625 & 3 & 10 & 5,22 & 7,5 & 6,269 & B \\
\hline 14.1 & 5 & 7 & 10 & 7,13 & 7,5 & 7,326 & B \\
\hline 15.1 & 6,25 & 0 & 0 & 8,09 & 7,5 & 4,368 & R \\
\hline 16.1 & 4,375 & 7 & 10 & 6,65 & 0 & 5,605 & B \\
\hline 17.1 & 6,25 & 7 & 7 & 7,61 & 5 & 6,572 & B \\
\hline 18.1 & 5,625 & 7 & 10 & 7,61 & 7,5 & 7,547 & B \\
\hline 19.1 & 5,625 & 7 & 7 & 5,22 & 7,5 & 6,469 & B \\
\hline 20.1 & 5 & 7 & 7 & 7,13 & 0 & 5,226 & B \\
\hline
\end{tabular}




\begin{tabular}{|c|c|c|c|c|c|c|c|}
\hline 21.1 & 6,25 & 7 & 7 & 6,65 & 2,5 & 5,88 & $B$ \\
\hline 22.1 & 5 & 7 & 7 & 7,61 & 7,5 & 6,822 & $B$ \\
\hline 23.1 & 5 & 7 & 7 & 7,13 & 7,5 & 6,726 & B \\
\hline 24.1 & 6,875 & 7 & 10 & 7,13 & 10 & 8,201 & $\mathrm{MB}$ \\
\hline 25.1 & 8,125 & 3 & 7 & 5,21 & 2,5 & 5,167 & $B$ \\
\hline 26.1 & 5,625 & 7 & 7 & 6,66 & 7,5 & 6,757 & $B$ \\
\hline 27.1 & 6,25 & 3 & 3 & 7,61 & 2,5 & 4,472 & $R$ \\
\hline 28.1 & 5,625 & 7 & 0 & 3,79 & 7,5 & 4,783 & $R$ \\
\hline 29.1 & 6,25 & 3 & 10 & 6,17 & 7,5 & 6,584 & $B$ \\
\hline 30.1 & 5,625 & 3 & 3 & 7,13 & 7,5 & 5,251 & $B$ \\
\hline 31.1 & 6,25 & 7 & 7 & 8,57 & 7,5 & 7,264 & $B$ \\
\hline 32.1 & 5,625 & 7 & 10 & 6,18 & 7,5 & 7,261 & B \\
\hline 1.2 & 7,5 & 7 & 10 & 6,19 & 0 & 6,138 & $B$ \\
\hline 2.2 & 3,125 & 7 & 7 & 6,18 & 5 & 5,661 & B \\
\hline 3.2 & 6,25 & 7 & 10 & 5,7 & 0 & 5,79 & $B$ \\
\hline 4.2 & 5,625 & 7 & 10 & 7,13 & 10 & 7,951 & $\mathrm{MB}$ \\
\hline 5.2 & 5,625 & 10 & 7 & 7,14 & 5 & 6,953 & $B$ \\
\hline 6.2 & 5,625 & 3 & 7 & 8,57 & 10 & 6,839 & $B$ \\
\hline 7.2 & 7,5 & 7 & 10 & 6,18 & 7,5 & 7,636 & $\mathrm{MB}$ \\
\hline 8.2 & 3,75 & 7 & 10 & 6,65 & 10 & 7,48 & $B$ \\
\hline 9.2 & 6,875 & 7 & 10 & 7,13 & 7,5 & 7,701 & $B$ \\
\hline 10.2 & 5 & 7 & 7 & 6,66 & 2,5 & 5,632 & $B$ \\
\hline 11.2 & 5 & 10 & 7 & 5,22 & 7,5 & 6,944 & $B$ \\
\hline 12.2 & 3,125 & 10 & 7 & 7,13 & 2,5 & 5,951 & $B$ \\
\hline 13.2 & 5 & 7 & 7 & 7,13 & 5 & 6,226 & $B$ \\
\hline 14.2 & 6,25 & 7 & 10 & 7,14 & 7,5 & 7,578 & $B$ \\
\hline 15.2 & 6,25 & 7 & 7 & 6,65 & 5 & 6,38 & $B$ \\
\hline 16.2 & 4,375 & 7 & 10 & 8,09 & 5 & 6,893 & $B$ \\
\hline 17.2 & 6,25 & 7 & 10 & 7,14 & 5 & 7,078 & $B$ \\
\hline 18.2 & 5 & 7 & 10 & 8,57 & 10 & 8,114 & $\mathrm{MB}$ \\
\hline 19.2 & 4,375 & 10 & 3 & 7,13 & 5 & 5,901 & $\mathrm{~B}$ \\
\hline 20.2 & 3,75 & 7 & 3 & 7,14 & 10 & 6,178 & B \\
\hline 21.2 & 5 & 7 & 10 & 4,27 & 7,5 & 6,754 & $B$ \\
\hline 22.2 & 5,625 & 7 & 0 & 6,18 & 7,5 & 5,261 & $B$ \\
\hline 23.2 & 6,875 & 7 & 3 & 4,73 & 0 & 4,321 & $R$ \\
\hline 24.2 & 6,25 & 7 & 3 & 5,7 & 5 & 5,39 & $B$ \\
\hline 25.2 & 3,75 & 3 & 10 & 6,19 & 2,5 & 5,088 & $R$ \\
\hline 26.2 & 5 & 10 & 10 & 5,7 & 2,5 & 6,64 & $B$ \\
\hline 27.2 & 6,25 & 3 & 3 & 6,66 & 10 & 5,782 & B \\
\hline 28.2 & 3,75 & 7 & 7 & 6,65 & 0 & 4,88 & $R$ \\
\hline 29.2 & 5 & 7 & 7 & 7,13 & 2,5 & 5,726 & B \\
\hline 30.2 & 6,25 & 3 & 10 & 6,18 & 5 & 6,086 & $B$ \\
\hline 31.2 & 3,125 & 7 & 10 & 4,27 & 2,5 & 5,379 & $B$ \\
\hline
\end{tabular}

Fonte: Elaborada pelos autores (2020). 
Percebemos que o afeto precisa ser vivenciado em sala de aula, uma vez que é ele o responsável por modificar a qualidade do aprendizado. As emoções envolvidas ajudam nos processos químicos, elétricos, biológicos e sociais que experienciamos. Vivenciar experiências que amamos determina nossa qualidade de vida. Todos encontram-se aptos para aprender quando amam, desejam e são felizes (CUNHA, 2008). Conduzir uma aula com amor, deixando evidente essa postura, pode estimular uma vivência saudável e uma rotina escolar mais prazerosa para todos os envolvidos.

Paulo Freire (1996) nos traz a ideia de que querer bem os alunos é importante no processo de ensino-aprendizagem, dentro de limitações do docente:

Esta abertura ao querer bem não significa, na verdade, que, porque professor, me obrigo a querer bem a todos os alunos de maneira igual. Significa, de fato, que a afetividade não me assusta, que não tenho medo de expressá-la. Significa esta abertura ao querer bem a maneira que tenho de autenticamente selar o meu compromisso com os educandos, numa prática específica do ser humano (FREIRE, 1996, p. 159).

As crianças e jovens mostram-nos várias facetas e nos exigem múltiplos olhares, o que para nós pode parecer difícil, uma vez que temos uma formação calcada predominantemente nos princípios e nas concepções autoritárias (SABINO, 2012).

\section{CONSIDERAÇÕES FINAIS}

O estudo buscou formas de diagnosticar por mapeamento e geração de conceitos o perfil emocional dos alunos. Com esses dados, os professores poderão estabelecer um novo olhar para o aluno que apresenta lacunas de cunho social e emocional e verificar individualmente, pelo material das oficinas, qual a melhor maneira de trabalhar com ele, estabelecendo laços emocionais que contribuam para o processo de ensino-aprendizagem.

Após a aplicação das oficinas de afetividade e da constituição do índice, é essencial fazer dinâmicas e atividades que desenvolvam o equilíbrio emocional do grupo. Medir dados de avaliação dos alunos pode ser útil para testar a qualidade e eficácia das atividades desenvolvidas pós-oficinas. Além disso, para que esta atividade tenha êxito é essencial que seja trabalhado e de conhecimento de todos os professores da escola, tornando-se interdisciplinar.

Os alunos envolvidos nas oficinas aplicadas para este estudo mostraram-se bastante engajados e participativos. Notamos que alguns não expuseram seus maiores problemas e dificuldades de caráter socioemocionais em todas as oficinas, mas eles sempre apareceram de alguma forma.

Percebemos que a realização das oficinas estabeleceu um vínculo interessante entre alunos e professor aplicador, posto que eles relatavam muitas vivências e histórias pessoais, inclusive demonstrando e externalizando sentimentos e sensações, tais como: choro, risos, tristeza e alegria. A possibilidade de falar sobre determinadas aflições e sentimentos trouxe a abertura para uma comunicação mais ampla e significativa potencializando e ampliando o processo de ensino-aprendizagem. 
A construção de uma didática mais humanística, respaldada em estudos nas áreas da neurociência, educação e psicologia, oriundos de educadores renomados e contemporâneos que trazem a afetividade aliada ao cognitivo, é necessária para aplicação de práticas e estímulos significativos ao processo complexo de aprendizagem. Dados emocionais servem de base para tal construção na prática docente e estimulam a formação de cidadãos críticos, éticos e humanos para uma sociedade carente de afetos na qual estamos inseridos.

\section{REFERÊNCIAS}

ABED, A. O desenvolvimento das habilidades socioemocionais como caminho para a aprendizagem e o sucesso escolar de alunos da educação básica. São Paulo: Unesco; MEC, 2016. Disponível em: http://pepsic. bvsalud.org/scielo.php?script=sci_arttext\&pid=S1415-69542016000100002. Acesso em: 28 mar. 2020.

AMORIM, M. C. S.; NAVARRO, E. C. Afetividade na Educação Infantil. Interdisciplinar: Revista Eletrônica da Univar, n. 7, p. 1-7, 2012. Disponível em: http://www.academia.edu/download/32535621/afetividade_educacao_infantil.pdf. Acesso em: 28 mar. 2020.

BORGES, M. L. Uma tipologia do amor na filosofia Kantiana, UFSC, p. 19-34, in: Studia Kantiana, 2(1), 2000. Disponível em: https://www.redalyc.org/pdf/934/93412807005.pdf. Acesso em: 21 dez. 2019.

CONSENZA, R. M.; GUERRA, L. B. Neurociência e educação: como o cérebro aprende. Porto Alegre, RS: Artmed, 2011. $148 \mathrm{p}$.

CUNHA, A. E. Afeto e aprendizagem, relação de amorosidade e saber na prática pedagógica. Rio de Janeiro: Wak, 2008.

DAMÁSIO, A. Em busca de Espinosa: prazer e dor na ciência dos sentimentos. São Paulo: Companhia das Letras, 2004.

FONSECA, J. J. S. Metodologia da pesquisa científica. Fortaleza: UEC, 2002. (Apostila).

FRAGA, C. C.; DECARLI, C. Amorismo: visualizando a afetividade no espaço escolar através da visão discente. Revista Acadêmica Licencia\&acturas, v. 6, n. 1, 2018. p. 95-103.

FREIRE, P. Pedagogia da autonomia. São Paulo: Paz e Terra, 1996.

FREITAS, K. R.; DIAS, S. M. Z. Percepções de adolescentes sobre sua sexualidade. Texto \& Contexto Enfermagem, 19(2), p. 351-357, 2010. Disponível em: http://www.scielo.br/pdf/tce/v19n2/17.pdf. Acesso em: 19 nov. 2019.

JUNIOR, F. C. Oficina de afeto. 2006. Disponível em: https://www.oficinadeafeto.com/. Acesso em: 28 dez. 2019.

OLIVEIRA, J. H. B. Psicologia positiva. Porto: ASA, 2004.

PANTANO, T.; ASSENCIO-FERREIRA, V. J. Introdução às neurociências. In: PANTANO,T.; ZORZI, J. L. (org.). Neurociência aplicada à aprendizagem. São José dos Campos: Pulso, 2009. p. 11-22.

RIBEIRO, M. L. A afetividade na relação educativa. Estudos de Psicologia, 27 (3), p. 403-412, 2010. Disponível em: http://www.scielo.br/scielo.php?pid=S0103-166X2010000300012\&script=sci_arttext. Acesso em: 20 mar. 2020.

SABINO, S. O afeto na prática pedagógica e na formação docente. Uma presença silenciosa. São Paulo: Paulinas, 2012.

SAFATLE, V. O circuito dos afetos: corpos políticos, desamparo e o fim do indivíduo. 2. ed. São Paulo-SP: Autêntica, 2016. 360 p.

SANTOS, D.; PRIMI, R. Desenvolvimento socioemocional e aprendizado escolar: uma proposta de mensuração para apoiar políticas públicas. São Paulo: Instituto Ayrton Senna, 2014.

SARNOSKI, E. A. Afetividade no processo ensino-aprendizagem. Rei - Revista de Educação do Ideau, v. 9, n. 20, 2014. Disponível em: https://www.caxias.ideau.com.br/wp-content/files_mf/0591228939ab3bddbe3d293fc78a6251223_1.pdf. Acesso em: 25 mar. 2020.

SASIKUMAR, N.; FATHIMA, M. P.; MOHAN, S. Emotion and Learning: a theoretical Framework of Cognitive Neuroscience. International Journal of Social Science Tomorrow, v. 2, n. 11, 2013. Disponível em: https:// www.researchgate.net/profile/Sasi_Kumar119/publication/329705991_Emotion_and_Learning_A_Theoretical_Framework_of_Cognitive_Neuroscience/links/5c1739a04585157ac1c7c1b7/Emotion-and-Learning-A-Theoretical-Framework-of-Cognitive-Neuroscience.pdf. Acesso em: 10 dez. 2019. 
SILVA, M. L.; CRUZ, V. A.; SILVA, F. F. A dimensão afetiva e sua relevância no processo de ensino-aprendizagem: uma abordagem sociocognitiva. Revista Eletrônica em Gestão, Educação e Tecnologia Ambiental - Reget, v. 18, n. 3, p. 1.303-1.311, 2014. Disponível em: https://periodicos.ufsm.br/index.php/reget/article/view/14045. Acesso em: 10 dez. 2019.

TYNG, C. M.; AMIN, H. U.; SAAD, M. N. M.; MALIK, A. S. The Influences of Emotion on Learning and Memory. Front. Psychol., 8, p. 1.454. DOI: 10.3389/fpsyg.2017.01454, 2017. Disponível em: https://www.frontiersin.org/articles/10.3389/fpsyg.2017.01454/full. Acesso em: 19 nov. 2019.

VINCENT, J-D. The Biology of Emotions. Cambridge, Mass.: Basil Blackwell, 1990.

VYGOTSKY, L. S. Psicologia pedagógica. Porto Alegre: Artmed, 2003. 